\title{
Creatine Supplementation and Its Effect on Musculotendinous Stiffness and Performance
}

\author{
MARK L. WATSFORD, ${ }^{1}$ ARON J. MURPhY, ${ }^{1}$ WARWICK L. SPINKS, ${ }^{1}$ AND \\ ANDREW D. WALSHE ${ }^{2}$
}

${ }^{1}$ Human Movement Department, School of Leisure, Sport, and Tourism, University of Technology, Sydney, Australia 2070; ' United States Ski and Snowboard Association, Park City, Utah 84060.

\begin{abstract}
Anecdotal reports suggesting that creatine $(\mathrm{Cr})$ supplementation may cause side effects, such as an increased incidence of muscle strains or tears, require scientific examination. In this study, it was hypothesized that the rapid fluid retention and "dry matter growth" evident after Cr supplementation may cause an increase in musculotendinous stiffness. Intuitively, an increase in musculotendinous stiffness would increase the chance of injury during exercise. Twenty men were randomly allocated to a control or an experimental group and were examined for musculotendinous stiffness of the triceps surae and for numerous performance indices before and after $\mathrm{Cr}$ ingestion. The $\mathrm{Cr}$ group achieved a significant increase in body mass $(79.7 \pm 10.8 \mathrm{~kg}$ vs. $80.9 \pm 10.7$ $\mathrm{kg})$, counter movement jump height $(40.2 \pm 4.8 \mathrm{~cm}$ vs. 42.7 $\pm 5.9 \mathrm{~cm})$, and $20-\mathrm{cm}$ drop jump height $(32.3 \pm 3.3 \mathrm{~cm}$ vs. $35.1 \pm 4.8 \mathrm{~cm}$ ) after supplementation. No increase was found for musculotendinous stiffness at any assessment load. There were no significant changes in any variables within the control group. These findings have both performance- and injury-related implications. Primarily, anecdotal evidence suggesting that $\mathrm{Cr}$ supplementation causes muscular strain injuries is not supported by this study. In addition, the increase in jump performance is indicative of performance enhancement in activities requiring maximal power output.
\end{abstract}

Key Words: series elastic component, performance enhancement, ergogenic aid, muscle strain

Reference Data: Watsford, M.L., A.J. Murphy, W.L. Spinks, and A.D. Walshe. Creatine supplementation and its effect on musculotendinous stiffness and performance. J. Strength Cond. Res. 17(1):26-33. 2003.

\section{Introduction}

Numerous research studies have examined the effects of creatine $(\mathrm{Cr})$ supplementation on athletic performance and have reported increased strength, power, and body mass (BM) $(10,23)$. The 2 proposed mechanisms for this performance enhancement are (a) an enhanced storage of phosphocreatine, leading to improved energy levels that contribute to an enhanced force and power output $(11,16,24)$ and (b) a more rapid and efficient recovery period $(11,16,18)$.

The performance-enhancing aspects of $\mathrm{Cr}$ are well documented; however, anecdotal reports suggest that $\mathrm{Cr}$ supplementation may cause numerous, harmful side effects. Susceptibility to renal problems, gastrointestinal disturbances, cardiovascular problems, and an increased risk of soft tissue injury have been the focus of anecdotal reports, and attention must be paid to these risks to ensure the safety of this widely used substance (28). The only proven side effect of $\mathrm{Cr}$ supplementation is an increase in BM, with speculation surrounding other possible side effects. This demonstrates the distinct need for controlled research in this area. This study focuses on the issue that $\mathrm{Cr}$ may increase the risk of muscular injury.

It has been reported that increased strength is associated with an increase in the stiffness of the musculotendinous unit (29). This was reportedly due to an increased activation of cross-bridges. In addition, previous research has demonstrated an increase in fluid retention $(12,23)$ and dry matter growth $(14)$ after $\mathrm{Cr}$ supplementation. Such changes may, in theory, alter the viscoelastic properties of the series elastic component (SEC) of skeletal muscle. The SEC provides the link between the muscular system and the skeletal system; hence, the stiffness of this component determines numerous performance- and injury-related indices (39). A relatively stiff musculotendinous unit theoretically predisposes the individual to a greater risk of injury when compared with a compliant unit (39).

This study hypothesizes that the expected increase in strength associated with $\mathrm{Cr}$ supplementation, when coupled with the proposed alterations in the stiffness of SEC after $\mathrm{Cr}$ supplementation, may cause a significant increase in musculotendinous stiffness. Intuitively, such an adaptation would increase the risk of soft tissue injury. Because of the paucity of data examining the effects of $\mathrm{Cr}$ on rate of force development (RFD) and reactive strength, these facets of performance were examined in this study. 


\section{Methods}

\section{Experimental Approach to the Problem}

By design, this study attempted to quantify any alterations to muscular strength after a $\mathrm{Cr}$-supplementation program. This research also attempted to quantify any alterations to SEC of the muscle after $\mathrm{Cr}$ supplementation. An examination of these 2 variables would provide an insight into the potential injury risks associated with $\mathrm{Cr}$ supplementation. Alterations in measures of strength, musculotendinous stiffness, RFD, and various performance measures were assessed before, during, and at completion of a standard $\mathrm{Cr}$-supplementation protocol. The study was a randomized, placebocontrolled double-blind design. Musculotendinous stiffness was assessed using methodology previously implemented and validated $(32,37,39)$, and the performance variables assessed reflected powerful, highintensity activities. Because of the expected increase in "ength after $\mathrm{Cr}$ supplementation, maximal isometric .urce was measured on an instrumented calf raise maine in addition to maximal RFD. The alterations evidenced in such properties would confirm the uptake of $\mathrm{Cr}$ by the body. Previous research has found a link between increased musculotendinous stiffness and muscle strength; hence, the proposed increases in muscle strength associated with a Cr-supplementation program were examined in conjunction with musculotendinous stiffness.

\section{Subjects}

To investigate the proposed risks and the performance-enhancing capabilities of $\mathrm{Cr}, 22$ healthy men (age, weight, and height were $23.4 \pm 4.9$ years, $79.4 \pm$ $12.2 \mathrm{~kg}$, and $176.4 \pm 7.2 \mathrm{~cm}$, respectively) were examined for musculotendinous stiffness, isometric force, RFD, counter movement jump (CMI), and drop $\therefore \mathrm{mp}$ (DJ) performance. The $\mathrm{Cr}$ group ingested 20

${ }^{-1}$ of $\mathrm{Cr}$ for 7 days followed by $10 \mathrm{~g} \cdot \mathrm{d}^{-1}$ for 21 days. introl subjects underwent an identical protocol by ingesting a placebo. The $\mathrm{Cr}$-ingestion protocol was similar to that of previous research (19) and consisted of a loading phase and a maintenance phase. Doses were administered in premeasured vials to ensure accuracy. No exercise was prescribed during the ingestion phase, and participants were instructed to maintain normal activity levels. Tests were undertaken before $\mathrm{Cr}$ ingestion (pretest), following the 7-day loading phase (midtest), and at completion of the 28-day ingestion period (posttest). The scientists did not implement a crossover design because the presence of a control group was deemed to overcome the need for such a treatment. The participants completed a preparticipation consent form, and the testing procedures were approved by the UTS Human Research Ethics Committee.

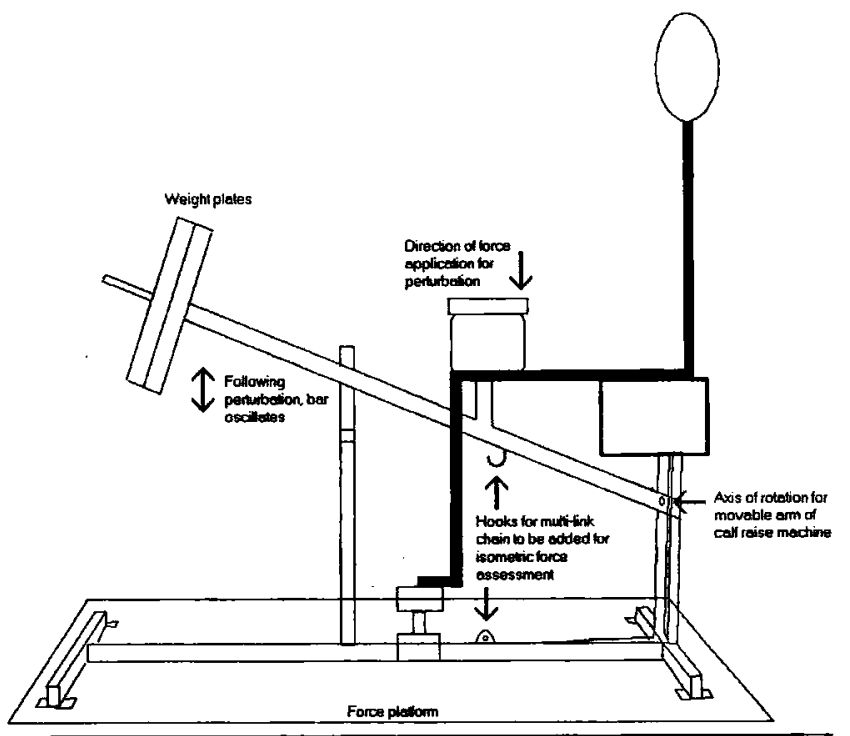

Figure 1. The instrumented calf raise machine used for musculotendinous stiffness assessment and isometric force assessment. Knee and ankles angles were maintained at $90^{\circ}$

\section{Physiological Tests}

Body Mass. The BM of each participant was assessed at each testing session using calibrated electronic scales (Hycom Equipment, Sydney, Australia) for 2 purposes: (a) assessment of fluctuations in BM associated with a Cr-supplementation program and (b) load determination for participants during assessment of musculotendinous stiffness to ensure that the loads were relative to $\mathrm{BM}$.

Isometric Force and Rate of Force Development. Assessment of triceps surae strength was performed using a maximal isometric contraction. The test was performed on an instrumented seated calf raise machine (Figure 1), with the ankle and knee joints placed in a neutral $\left(90^{\circ}\right)$ position. The participants were instructed to exert force as hard and as quickly as possible and to hold it for 3 seconds. Force data were recorded at $1,000 \mathrm{~Hz}$ by a load cell (Chase Engineering, Sydney, Australia), which was positioned between the ground and the movable arm of the calf raise machine. From this data, the maximum force and RFD ( $5 \mathrm{~ms}$ average) were calculated. Two trials were conducted at each session, with rest allowed between trials, and the average of the trials was used. The triceps surae musculature was examined for a number of reasons including: (a) the nature of consistent submaximal and maximal loading this muscle group receives, (b) the implications for running and jump performance inherent in this muscle group, and (c) the relative ease of isolation of this muscle group. The bar height and position over the knees were standardized for each participant. Different lower-leg lengths were taken into consideration for each participant using a multi- 
link chain in which links could be added and removed as required.

Musculotendinous Stiffness. Assessment of musculotendinous stiffness was performed using the oscillation technique $(7,32,39)$, in a position that was identical to that used in the isometric force assessment. This position isolated the triceps surae musculature, thereby providing the opportunity for examination of the relationship between musculotendinous stiffness and force in the triceps surae. The oscillation technique involves the assumption that human muscle is modeled as a damped spring system and that any perturbation to a loaded system will result in oscillations containing a damping element due to the viscoelastic properties of the muscle and tendon. The participants supported a load, that was calculated as a percentage of BM using the triceps surae musculature, and attempted to maintain a $90^{\circ}$ angle at the ankle. A brief perturbation of the order of 100-200 N was applied, and the ensuing oscillations were recorded. According to several authors $(32,37,39)$, the system will oscillate at its natural frequency regardless of the magnitude of the perturbation.

The oscillations were modeled according to a second-order linear equation of the form:

$$
\frac{m d^{2} x}{d t^{2}}+\frac{c d x}{d t}+k x=m g
$$

where $x$ is the displacement of the system, $g$ the acceleration due to gravity, and $m$ the mass of the system.

Equations were applied to the data to assess the frequency of oscillations $(f)$, the damping coefficient $(c)$, the natural frequency of the system $\left(f_{n}\right)$, and the stiffness of the system $(k)$. Various loads were added to the calf raise machine for assessment. These were the equivalent of 50,100 , and $200 \%$ of $\mathrm{BM}(50,100$, and $200 \% \mathrm{BM}$, respectively) at the point of force transmission to the lower leg. For each load, 2 trials were completed and averaged for each testing session. Rest periods of 2-3 minutes were allowed between all trials. A standard warm-up was used at each test occasion because warm-up has been shown to affect musculotendinous stiffness $(26,39)$.

Validity and reliability assessment of the instrumented calf raise machine were performed before the research. The reliability of the calf raise machine was assessed by examination of interday musculotendinous stiffness values. Participants underwent 2 assessment sessions separated by no more than 7 days, involving musculotendinous stiffness assessment at loads corresponding to 50,100 , and $200 \% \mathrm{BM}$. There were no interday differences as measured by Pearson's product moment analysis $(r=0.91, p<0.05)$. Validity tests required the participants to perform tests to examine RFD and the capacity to benefit from a previous stretch, termed the prestretch augmentation ((CMJ SJ) $/ \mathrm{SJ} \times 100$ ), for comparison with the musculotendinous stiffness data. Significant correlations were evident for both these facets $(r=0.66, p<0.05 ; r=$ $-0.65, p<0.05$, respectively), which are similar to the results of a previous study (36). The participants were then divided into a relatively stiff group and a relatively compliant group for assessment of DJ performance. The compliant group showed greater performance in the DJ $80-\mathrm{cm}$ and the DJ $100-\mathrm{cm}$ conditions, whereas the stiff group exhibited a decrease in performance from these drop heights, which also is in line with previous research (35).

\section{Statistical Analyses}

The sample size for this study was chosen based on the gain in $\mathrm{BM}$ evidenced with $\mathrm{Cr}$ supplementation. The significance of the findings was examined by estimating the magnitude of the difference between the groups using a standardized value or effect size. Effect size is measured in relation to the principle assessment criterion; therefore, in this study, because of the paucity of data examining $\mathrm{Cr}$ and musculotendinous stiffness, the alterations to $\mathrm{BM}$ after $\mathrm{Cr}$ supplementation were analyzed to determine effect size. Based on previous research examining the effect of $\mathrm{Cr}$ on $\mathrm{BM}(10$, 24), it was assumed that the effect size for this study would be quite large (0.7-0.9). An $80 \%$ confidence level for rejection of the null hypothesis after the supplementation program was desired; hence, power was set at $0.8(\beta=1-0.2=0.8)$. Therefore, with an effect size of 0.8 and an alpha level of 0.05 , the sample size of 9 for each group is deemed to be adequate.

A 1-way analysis of variance (ANOVA) was used to determine differences between the 2 groups at the pretest in the dependent measures. This test yielded no differences between the groups before the commencement of the supplementation program. The posttest data were examined for normality of distribution, and a 2 (group) by 3 (test occasion) ANOVA with repeated measures on the tests factor was performed on the test data collected on each test occasion. Follow-up univariate contrasts (Bonferroni) were performed on significant effects to determine the significance of the pairwise comparisons or contrasts. A probability level of 0.05 was adopted for the study. Two subjects from the $\mathrm{Cr}$ group were omitted from the results for failure to comply with the supplementation protocol, reducing the number of participants to 20 , with 11 in the control group and 9 in the $\mathrm{Cr}$ group.

\section{Results}

As shown in Table 1, the $\mathrm{Cr}$ group achieved a $1.2 \mathrm{~kg}$ $(1.5 \%)(F=7.45, p<0.01)$ gain in $\mathrm{BM}$ at the posttest, which, in the absence of in vivo measurement and when compared with the dosages used in previous research, is indicative of an increase in intramuscular 
Table 1. Mean $\pm S D$ for $\mathrm{BM}$ and musculotendinous stiffness measures. Creatine group, $N=9$, Control group, $N=11$.

\begin{tabular}{clccc}
\hline \multicolumn{1}{c}{ Test } & Group & \multicolumn{1}{c}{ Pretest } & Midtest & Posttest \\
\hline BM+ $(\mathrm{kg})$ & Creatine & $79.7 \pm 10.8$ & $80.5 \pm 10.4$ & $80.9 \pm 10.7^{*}$ \\
& Control & $79.2 \pm 13.7$ & $78.8 \pm 13.3$ & $78.5 \pm 13.4$ \\
$50 \%$ BM stiffness $\left(\mathrm{N} \cdot \mathrm{m}^{-1}\right)$ & Creatine & $3,463.7 \pm 520.9$ & $3,440.1 \pm 470.4$ & $3,403.3 \pm 691.3$ \\
& Control & $3,407.6 \pm 617.2$ & $3,385.0 \pm 651.2$ & $3,311.2 \pm 603.8$ \\
$100 \%$ BM stiffness $\left(\mathrm{N} \cdot \mathrm{m}^{-1}\right)$ & Creatine & $5,199.7 \pm 789.0$ & $5,275.7 \pm 890.3$ & $4,902.6 \pm 962.6$ \\
& Control & $5,096.1 \pm 973.2$ & $4,978.4 \pm 908.9$ & $5,017.3 \pm 1,089.1$ \\
$200 \%$ BM stiffness $\left(\mathrm{N} \cdot \mathrm{m}^{-1}\right)$ & Creatine & $\mathbf{8 , 1 4 7 . 7 \pm 1 , 6 5 2 . 1}$ & $7,469.0 \pm 822.6$ & $7,086.2 \pm 1,055.6^{*}$ \\
& Control & $7,445.8 \pm 1,696.0$ & $7,513.9 \pm 1,805.4$ & $7,227.2 \pm 1,548.6$ \\
\hline
\end{tabular}

$+\mathrm{BM}=$ body mass.

* Significantly different from pretest value $(p<0.05)$.

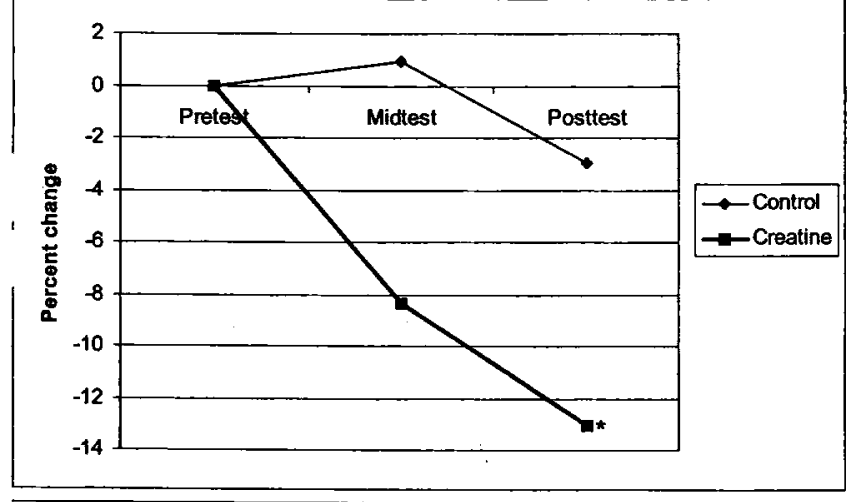

Figure 2. Musculotendinous stiffness at the highest assessment load exhibited a $13 \%$ decrease after the creatinesupplementation program. The control group remained unchanged $\left({ }^{*}\right.$ indicates a pre-post treatment effect, $\left.p<0.05\right)$.

PC stores. There were no significant alterations in BM between the pre- and midtest occasions or between the mid- and posttest occasions. Results of repeated measures ANOVA showed a significant $13 \%$ decrease in musculotendinous stiffness at the $200 \%$ BM load $(F=$ $-149, p<0.05$ ) at the posttest (Table 1 and Figure 2). - changes were evident at submaximal loads of 50 id $100 \%$ BM at either the mid- or the posttest occasions.

Table 2 illustrates the significant $2.5-\mathrm{cm}(6.1 \%)(F$ $=4.048, p<0.05$ ) increase in CMJ height after supplementation and the significant $2.8-\mathrm{cm}(8 \%)(F=$ $5.569, p<0.05)$ increase in DJ performance from 20 $\mathrm{cm}$, evident between the pre- and posttest data. There were no significant alterations in RFD; however, an increasing trend $(5 \%)(F=1.995, p>0.05)$ for isometric force production was demonstrated. Two additional increasing trends were evident in the measures of the $40-\mathrm{cm}$ and $60-\mathrm{cm}$ DJ performance, 5.5 and $3.7 \%$, respectively. Additional DJ measures of ground contact time (CT) and height-CT index showed no significant alterations. There were no significant changes in any variables within the control group in the pre- to midtest or the pre- to posttest data.

\section{Discussion}

This study showed that BM of the Cr group increased by $1.2 \mathrm{~kg}$ (Table 1). Previous research has shown that Cr supplementation increases BM in the order of 0.9 $4.8 \mathrm{~kg}(2,10,12,14,23)$. The dosage administered in this study was similar to that used in previous studies, with $20 \mathrm{~g} \cdot \mathrm{d}^{-1}$ being ingested by the participants for 7 days followed by $10 \mathrm{~g} \cdot \mathrm{d}^{-1}$ for a further 21 days. In the absence of direct $\mathrm{Cr}$ measurement, it is believed that the significant gain in mass in the $\mathrm{Cr}$ group after the completion of the 28-day Cr-supplementation period is indicative of significant uptake of $\mathrm{Cr}$ by the body.

The mechanism behind this gain in mass is presently unknown; however, 2 major factors have emerged in the literature, namely, water retention and dry matter growth. The water retention argument has been supported by research (20) claiming that $\mathrm{Cr}$ is an osmotically active substance and that an alteration in intracellular $\mathrm{Cr}$ quantities may induce cellular swelling. This argument was supported by further research (21) that showed a decreased urinary output during a Cr-supplementation program and a resulting increase in BM that was attributed to an increase in water retention. Conversely, other authors $(14,15)$ reported that the gain in mass was due to dry matter growth associated with normal water levels in the body. As such, if the results of this study are interpreted in this context, the change in BM would not merely be a transient shift in water volume but would be a hypertrophic response of muscle tissue and hence a chronic rather than an acute response. Further support for these results (9) has been found in rats, where $\mathrm{Cr}$ supplementation causes muscular hypertrophy, thereby promoting increased strength.

The results of this study further support previous findings that $\mathrm{Cr}$ supplementation increases BM. Athletes desiring a gain in muscle size, strength, and bulk can use $\mathrm{Cr}$ to achieve an increase in BM of the order of 1-2 kg over relatively short time periods. These re- 
Table 2. Mean $\pm S D$ for performance measures. Creatine group $N=9$, Control group $N=11$.

\begin{tabular}{llccc}
\hline \multicolumn{1}{c}{ Test } & Group & Pretest & Midtest & Posttest \\
\hline Counter movement jump $(\mathrm{cm})$ & Creatine & $40.2 \pm 4.8$ & $41.4 \pm 3.4$ & $42.7 \pm 5.9^{*}$ \\
& Control & $39.1 \pm 6.0$ & $39.2 \pm 7.2$ & $39.5 \pm 7.2$ \\
Isometric force $(\mathrm{N})$ & Creatine & $2,908.8 \pm 475.3$ & $2,958.5 \pm 420.2$ & $3,086.8 \pm 625.3$ \\
& Control & $3,037.7 \pm 762.5$ & $3,087.1 \pm 712.9$ & $3,024.4 \pm 632.5$ \\
Rate of force development $\left(\mathrm{N} \cdot \mathrm{s}^{-1}\right)$ & Creatine & $11,677 \pm 2,479$ & $11,356 \pm 3,332$ & $11,682 \pm 3,029$ \\
& Control & $12,646 \pm 4,219$ & $12,424 \pm 3,854$ & $12,074 \pm 3,677$ \\
DJ20 height $(\mathrm{cm})$ & Creatine & $32.3 \pm 3.3$ & $33.8 \pm 3.8$ & $35.1 \pm 4.8^{*}$ \\
DJ40 height $(\mathrm{cm})$ & Control & $32.8 \pm 5.8$ & $33.5 \pm 5.9$ & $33.7 \pm 7.3$ \\
& Creatine & $34.6 \pm 3.2$ & $34.9 \pm 3.9$ & $36.5 \pm 6.0$ \\
DJ60 height $(\mathrm{cm})$ & Control & $34.0 \pm 6.3$ & $35.5 \pm 7.6$ & $35.5 \pm 8.3$ \\
& Creatine & $35.6 \pm 4.3$ & $36.3 \pm 3.3$ & $36.9 \pm 5.9$ \\
\hline
\end{tabular}

* Significantly different from pretest value $(p<0.05)$

sults are indicative of the possibility that $\mathrm{Cr}$ may adversely affect endurance performance (27). Endurance athletes should remain cautious regarding the use of $\mathrm{Cr}$ in a performance-enhancing role.

Musculotendinous stiffness values measured in this study were within the ranges previously reported by authors examining stiffness using the oscillation technique. Previous research revealed considerable variation, with values ranging from $7.5 \mathrm{kN} \cdot \mathrm{m}^{-1}$ to 20 $\mathrm{kN} \cdot \mathrm{m}^{-1}(26,32,35,39)$. The values reported in this study are in the lower bracket of these previous findings (Table 1); however, each muscle-tendon unit exhibits different stiffness values depending on the recruitment of motor units during testing, training history, and amount of warm-up undertaken $(13,26,37)$. A further explanation for the variance shown in these trials is that numerous techniques have been used to assẽss stiffness, with each technique using differing contraction types and levels, differing joint angles, and different mathematical models for analysis. Care must be taken when comparing absolute values among the literature. The triceps surae musculature was selected in this study because it is used regularly, experiences submaximal or maximal loading during upright tasks, may be easily isolated, and consists of both type-I and type-II muscle fibers.

This study reported no increase in musculotendinous stiffness at any assessment load (Table 1). It was hypothesized that an increased intracellular fluid content resulting from $\mathrm{Cr}$ intake would increase the stiffness of the musculotendinous unit, thereby increasing the risk of injury. However, within the limitations of this study, the findings clearly show that a 28-day $\mathrm{Cr}$ supplementation program does not place the individual in a position of increased risk of muscle injury as a result of an increased stiffness of the musculotendinous unit.

Given the results of this study, it is conceivable that other factors may be responsible for the anecdotally reported increased risk of injury. As exercise enhances the uptake of $\mathrm{Cr}$ by the muscles $(19,30)$, individuals participating in intense exercise programs while ingesting $\mathrm{Cr}$ may be placed at a higher risk for injury. In this study, no exercise was prescribed during the ingestion period because the authors wanted to isolate the effect of $\mathrm{Cr}$ uptake on risk of injury. Similarly, very high dosages of $\mathrm{Cr}$ also may place the individual at a greater risk for injury. It has been reported that some users have a mindset envisaging that if $20 \mathrm{~g} \cdot \mathrm{d}^{-1}$ of $\mathrm{Cr}$ yields good results then 3 times that amount will have 3 times the effect (6). Another factor that might explain increased risk of injury with $\mathrm{Cr}$ supplementation is that as $\mathrm{BM}$ increases, agonist-antagonist coordination may be altered causing problems associated with gait and other movement patterns. Further research is required to examine this issue.

In this study, the decrease in musculotendinous stiffness at the $200 \%$ BM (Table 1) load may be explained methodologically. Examination of strength measures after $\mathrm{Cr}$ supplementation showed that whereas isometric strength was not significantly increased after the $\mathrm{Cr}$-supplementation program, a trend toward increased force, with a nonsignificant $5 \%$ improvement, was evident within the Cr group. Numerous research studies have shown an increase in strength after a $\mathrm{Cr}$-supplementation program $(4,10$, $23-25,34)$. Therefore, it is postulated that the increasing trend in isometric strength was sufficient to affect the stiffness assessment at the highest load, such that the load was relatively lighter for the participant as compared with that in the pretest occasion. This relatively lighter load at the posttest led to a decrease in the neural drive to the muscle and resulted in decreased cross-bridge formation, thereby decreasing the stiffness of the musculotendinous unit (13).

Based on the results of this study, it is concluded 
that mechanical factors related to increased musculotendinous stiffness play no role in increasing the risk of muscle strain injuries after $\mathrm{Cr}$ supplementation. Given the difficulty in isolating the direct mechanism of soft tissue injury after a Cr-supplementation program, assuming that the mechanism exists, it is proposed that further research be conducted in this area. Focal points for such a research would include the activities leading to the injury and the intramuscular location of the injury after a Cr-supplementation program. Importantly, the role of exercise during the $\mathrm{Cr}$ ingestion period must be examined, concentrating on both uptake of $\mathrm{Cr}$ by the body and risk of injury.

Performance tests yielded results similar to those discussed in previous research. Although isometric and isotonic muscular contractions rely on different mechanical properties for force production (38), both types of contractions have benefited from $\mathrm{Cr}$ supplementation. Creatine supplementation has been shown 'n improve isometric force production by up to $10 \%$

$4,25)$ and isotonic strength by up to $26 \%(4,12,23$, ${ }^{-4)}$ in subjects who underwent strength training. In .nis study, the results of isometric force proved to be inconsistent with those of previous research, with results for the $\mathrm{Cr}$ group failing to reach statistical significance. However, a trend toward increased strength (5\%) was evident, which may have reached significance had the participants been prescribed exercise during the supplementation time. Participation in exercise during $\mathrm{Cr}$ supplementation has been shown to enhance uptake levels up to a certain level $(17,19)$. A previous study has hypothesized that exercise either promotes blood flow to the active skeletal muscles, thereby increasing the amount of free $\mathrm{Cr}$ available for absorption by the muscle, or leads to a greater efficiency in the transport kinetics of $\mathrm{Cr}$ across the fiber membrane (19). When examining isometric force, it is important to note that isometric strength testing by - ature is not specific to concentric muscle actions (1).

2 isoinertial properties of concentric and eccentric ntractions differ from those of isometric contracuons. Despite this fact, previous research on musculotendinous stiffness has used this method of testing $(35,39)$ because of its practicality and strength measurement at the approximate angle of musculotendinous stiffness.

Rate of force development showed no significant changes after the $\mathrm{Cr}$-supplementation program (Table 2). The analysis of the results of musculotendinous stiffness provides an explanation for these findings. According to Wilson et al. (38), a high RFD is reliant on a relatively stiff muscle-tendon unit, which permits greater lengthening of the contractile component of the muscle as the unit extends. Improved length-tension and force velocity conditions facilitate rate of production of force. Theoretically, a decrease in musculotendinous stiffness would serve to depress the velocity of the force that is transmitted between the contractile component of the muscle and the osteotendinous junction. No such phenomenon was evident from RFD results. The results of musculotendinous stiffness were in agreement with those of RFD, indicating that there were no alterations in SEC as a result of the Cr-supplementation program.

Counter movement jump performance exhibited a significant change in the Cr-supplementation program. A significant $6.1 \%$ (Table 2) increase was evident on completion of the 28-day ingestion period, which is in accordance with previous studies $(5,15,31,33)$. Given that there were no changes in the musculotendinous unit or in isometric strength after $\mathrm{Cr}$ supplementation, the mechanism by which CMJ improved appears to have its origin in the strength gains from other means, including muscular hypertrophy (9). Previous research examining the effect of $\mathrm{Cr}$ on single $\mathrm{CMJ}$ trials has attributed the gain in performance to improved power output as a result of increased intramuscular PC stores in combination with a training stimulus (22).

An increase in DJ performance was evident in the posttest condition, with DJ height from the $20-\mathrm{cm}$ condition exhibiting a significant $8.7 \%$ increase (Table 2). Interestingly, as was the case in CMJ performance, the increase in the $20-\mathrm{cm}$ jump height for DJ is evident despite an increase in $\mathrm{BM}$ and no prescribed training. The instructions for the DJ tests were to minimize ground CT. This instruction ensured that this test was a measure of reactive strength in a situation where the triceps surae musculature was responsible for primary force production.

The proposed mechanism for this increase in performance was related to the fact that a $20-\mathrm{cm}$ drop height represents a relatively low eccentric loading condition, which is an activity that is similar to CMJ; hence, improvements in this performance measure may be attributed to the same mechanism that is assumed to improve CMJ. In comparison, under conditions of high eccentric load, e.g., DJ $60 \mathrm{~cm}$, performance was not significantly improved after $\mathrm{Cr}$ supplementation. These results indicate that $\mathrm{Cr}$ supplementation does not play a role in improving reactive strength under conditions of high load, whereas under conditions of relatively low eccentric loading, there may be enhancements in performance, e.g., CMJ and DJ $20 \mathrm{~cm}$. Therefore, activities such as gymnastics floor routines and high-impact plyometric training regimens may not benefit from a $\mathrm{Cr}$-supplementation program because the magnitude of the impulse of landing and the RFD required for such activities is greater than the adaptive mechanisms associated with a $\mathrm{Cr}$-supplementation program. This phenomenon has not been reported in previous literature, and further investigation is required to determine the performance-enhancing role of $\mathrm{Cr}$ in these situations. 


\section{Practical Applications}

The results of this study have numerous injury- and performance-related implications. An increase in the tension in SEC theoretically predisposes the individual to a greater risk of injury during both eccentric and concentric force production and dissipation situations. In this study, the stiffness of SEC did not increase when assessed under identical load conditions. This study found that a controlled Cr-supplementation program does not play a role in the hypothesized increased risk of soft tissue injury. Further supporting evidence that $\mathrm{Cr}$ does not cause an increased risk of injury is apparent from the performance results. A CMJ is a relatively slow stretch shorten cycle activity (>300 ms); hence, optimal performance is achieved with a relatively compliant musculotendinous system (38). In this study, performance in this activity increased after supplementation, indicating that there was no increase in stiffness during the course of the supplementation program. In addition, there were no changes to RFD during the course of the supplementation period. Therefore, if the anecdotal reports of increased risk of muscle strain injury associated with $\mathrm{Cr}$ ingestion are true, it would appear that the mechanism is not a change in the mechanics of the musculotendinous system. Further research is necessary to determine the validity of such anecdotal reports.

The performance implications stemming from this research are intriguing. The increase in CMJ and DJ $20 \mathrm{~cm}$ was observed after $\mathrm{Cr}$ supplementation without a prescribed exercise regimen being undertaken. In addition, these performance enhancements were evident despite a $1.5 \%$ increase in BM after the supplementation period. In activities where propulsion from the ground is required, performance would intuitively decrease when there is an increase in the magnitude of the mass being propelled. In this study, however, the ergogenic effect of $\mathrm{Cr}$ was greater than the increase in mass, indicating the importance this substance has in performance of activities requiring high levels of dynamic strength and relatively long ground contact times.

From the perspective of strength gain, this study showed that isometric strength and RFD did not exhibit a significant increase after $\mathrm{Cr}$ supplementation. Therefore, if the purpose of the $\mathrm{Cr}$-supplementation program is to increase strength, it should be undertaken in conjunction with appropriate strength training for optimal results.

\section{References}

1. ABE, T.; Y. KaWAKamt, S. IKEGAWA, H. KaNEHISA, AND T. FUKUNAGA. Isometric and isokinetic knee joint performance in Japanese alpine ski racers. J. Sports Med. Phys. Fitness 31:353 357. 1992.

2. BALSOM, P.D., S.D.R. HARRIDGE, K. SODERLUND, B. SJODIN, AND
B. EKвLOM. Creatine supplementation per se does not enhance endurance exercise performance Acta Physiol. Scand. 149:521523. 1993.

3. BBC NEws. Athletes Supplement Linked to Cancer. January 24, 2001. Available at: http://news.bbc.co.uk/1/hi/health/ 1134489.stm

4. BECQUE, M.D., J.D. LOCHMANN, AND D. MELROSE. Effect of creatine supplementation during strength training on 1RM and body composition. Med. Sci. Sport Exerc. 29:S146. 1997.

5. Bosco, C., J. Thanan, J. Pucspk, I. Kovacs, A. Gobossy, R. Colli, G. Pullitenti, C. Foti, M. VirU, AND A. ViRU. Effect of oral creatine supplementation on jumping and running performance. Int. J. Sports Med. 18:369-372. 1997.

6. BULLOCK, C. The Creatine Story. Radio National's Background Briefing. February 13, 2000.

7. Cavagna, G. Elastic bounce of the body. J. Appl. Physiol. 29: 279-282. 1970.

8. COOKE, W.H., AND W.S. BARNES. The influence of recovery duration on high-intensity exercise performance after oral creatine supplementation. Can. J. Appl. Physiol. 22:454-467. 1997.

9. DANGot, B., E. SCHULTZ, AND P.E. MOZDZIAK. Dietary creatine monohydrate supplementation increases satellite cell mitotic activity during compensatory hypertrophy. Int. J. Sports Med. 21:13-16. 2000.

10. Earnest, C.P., P.G. SNell, R. Rodriguez, A.L. Almada, AND T.L. MrTCHELL. The effect of creatine monohydrate ingestion on anaerobic power indices, muscular strength and body composition. Acta Physiol. Scand. 153:207-209. 1995.

11. EKBLOM, B. Effects of creatine supplementation on performance. Am. J. Sports Med. 24:S38-S39. 1996.

12. Engelhardt, M., G. NeUmanN, A. BerbalK, AND I. Reuter. Creatine supplementation in endurance sports. Med. Sci. Sport Exerc. 30:1123-1129. 1998.

13. FORD, L.E., A.F HUXLEY, AND R.M. SIMMONS. The relation between stiffness and filament overlap in stimulated frog muscle fibers. J. Physiol. (Lond.) 311:219-249. 1981.

14. Francaux, M., AND J.R. PoOrtmans. Effects of training and creatine supplement on muscle strength and body mass. Eur. J. Appl. Physiol. 80:165-168. 1999.

15. GolDBERG, P.G., AND P.J. BECHTEL. Effects of low dose creatine supplementation on strength, speed and power by male athletes. Med. Sci. Sports Exerc. 29:S251. 1997.

16. Greenhaff, P.L., A. Casey, A.H. Short, R.C. HarRis, K. SODERLUND, AND E. HULTMAN. Influence of oral creatine supplementation of muscle torque during repeated bouts of maximal voluntary exercise in man. Clin. Sci. 84:565-571. 1993.

17. GReENHAFF, P.L., M.E. Nevill, K. SODERLUND, K. BODIN, L.H. BoOBIs, C. Williams, and E. Hultman. The metabolic response of human type I and II muscle fibers during maximal treadmill sprinting. J. Physiol. 478:149-155. 1994.

18. Grindstaff, P.D., R.B. KReIDER, R. Bishop, M. Willón, L. WOOD, C. AlEXANDER, AND A.L. Almada. Effects of creatine supplementation on repetitive sprint performance and body composition in competitive swimmers. Int. J. Sport Nutr. 7:330345. 1997.

19. HARRIS, R.C., K. SODERLUND, AND E. HULTMAN. Elevation of creatine in resting and exercised muscle of normal subjects by creatine supplementation. Clin. Sci. 83:367-374. 1992.

20. Haussinger, D., E. Roth, F. LANG, AND W. GeroK. Cellular hydration state: An important determinant of protein catabolism in health and disease Lancet 341:1330-1332. 1993.

21. Hultman, E., K. Soderlund, J.A. Timmons, G. Cederblad, AND P.L. GREENHAFF. Muscle creatine loading in man. J. Appl. Physiol. 81:232-237. 1996.

22. KIRKSEY, K.B., B.J. WARREN, M.H. STONE, M.R. STONE, AND R.L. JOHNSON. The effects of six weeks of creatine monohydrate supplementation in male and female track athletes. Med. Sci. Sport Exerc. 29:S145. 1997. 
23. Kreider, R.B., M. Ferreira, M. Wilson, P. Grinstaff, S. Plisk, J. REINARDY, E. CANTLER, AND A.L. ALMADA. Effects of creatine supplementation on body composition, strength and sprint performance. Med. Sci. Sport Exerc. 30:73-82. 1998.

24. KuRosawa, Y., H. Iwane, T. Hamaoka, T. SHimomitsu, T. KaTSUMURA, T. SAKO, M. KUWAMORI, AND N. KimURA. Effects of oral creatine supplementation on high and low intensity grip exercise performance. Med. Sci. Sport Exerc. 29:S251. 1997.

25. Maganaris, C.N., and R.J. MaughaN. Creatine supplementation enhances maximum voluntary isometric force and endurance capacity in resistance trained men. Acta Physiol. Scand. 163:279-287. 1998.

26. MCNAIR, P.J., AND S. STANLEY. The effect of passive stretching and jogging on the series elastic muscle stiffness and range of movement at the ankle joint. Br. J. Sport Med. 30:313-318. 1996.

27. MURPHY, A.J., W.L. SPINKS, M.L. WATSFORD, AND D.A.B. RICHARDS. The effect of creatine supplementation on cardiovascular function and endurance performance. In: Proceedings of the Sports Medicine Australia conference, Brisbane, Australia, 2000. p. 110.

28. PoORTMans, J.R., AND M. FranCaux. Adverse effects of creatine supplementation: Fact or fiction? Sports Med. 30:155-170. 2000.

?9. Poussen, M., J. VAN Hoeke, AND F. Goubel. Changes in elastic characteristics of human muscle induced by eccentric exercise. J. Biomech. 23:343-348. 1990.

J. Preen, D., B. Dawson, C. GoOdman, J. Beilby, and S. Ching. A comparison of various creatine loading and maintenance protocols on total creatine accumulation in human skeletal muscle. In: Proceedings of the Fifth IOC Congress on Sport Science, Sydney, Australia, 1999. p. 247.
31. Ribeiro, B.V., B. Carvalho, and R.J. Ribeiro. Effects of oral supplementation of creatine on basketball players. Med. Sci. Sport Exerc. 29:S146. 1997.

32. SHORTEN, M.R. Muscle elasticity and human performance. Med. Sport Sci. 25:1-18. 1987.

33. STOUT, J.R., J. ECKERSON, D. NOONAN, G. MOORE, AND D. CULLEN. The effects of a supplement designed to augment creatine uptake on exercise performance and fat-free mass in football players. Med. Sci. Sport Exerc. 29:S251. 1997.

34. VOLEK, J.S., W.J. KRAEMER, J.A. BUSH, M. BOETES, T. INCLEDON, K.L. ClaRK, J.M. LYNCH, AND H.G. KNUTTGEN. Creatine supplementation: Effect on muscular performance during high intensity resistance exercise. Med. Sci. Sport Exerc. 28:S81. 1996.

35. WALSHE, A.D., AND G.J. WILSON. The influence of musculotendinous stiffness on drop jump performance. Can. J. Appl. Physiol. 22:117-132. 1997.

36. WALSHE, A.D., G.J. WILSON, AND A.J. MURPHY. The reliability and validity of a test of lower body musculotendinous stiffness. Eur. J. Appl. Physiol. 73:332-339. 1996.

37. WiLSON, G.J., B.C. ELLIOT, AND G.A. WOOD. Stretch shorten cycle performance enhancement through flexibility training. Med. Sci. Sport Exerc. 24:116-123. 1992.

38. WILSON, G.J., A.J. MURPHY, AND J. PrYor. Musculotendinous stiffness: Its relationship to eccentric, isometric and concentric performance. J. Appl. Physiol. 76:2714-2719. 1994.

39. WILSON, G.J., G.A. WOOD, AND B.C. ElLIOT. Optimal stiffness of the series elastic component in a stretch shorten cycle activity. J. Appl. Physiol. 70:825-833. 1991.

Address correspondence to Mark Watsford, mark.watsford@uts.edu.au. 